\title{
From Physical Pharmacy to Clinical Pharmacology
}

\author{
Masahiro NAKANO \\ Department of Clinical Pharmaceutics, Graduate School of Pharmaceutical Sciences, University \\ of Shizuoka, 52-1 Yada, Shizuoka 422-8526, Japan
}

(Received January 14, 2005)

\begin{abstract}
Research works on molecular interactions in solutions were carried out at School of Pharmacy, the University of Wisconsin under the direction of Prof. T. Higuchi and at Faculty of Pharmaceutical Sciences, Kyoto University under the direction of Prof. H. Sezaki. Studies on permeation of drugs through polymer membranes were carried out at Faculty of Pharmacy and Pharmaceutical Sciences, University of Alberta, Edmonton, Canada and at Pharmaceutical Chemistry Research Laboratories at Food and Drug Directorate, Department of Health and Welfare, Canada. Studies on modification of delivery patterns by means of pharmaceutical approaches were carried out at Faculty of Pharmaceutical Sciences, Hokkaido University. Topics related to modification of drug delivery patterns include employment of amorphous forms such as ground mixture with micro-crystalline cellulose and coprecipitate with polyvinylpyrrolidone, use of biodegradable polymers such as polylactic acid and polycarbonates, gel-forming materials such as konjac, agar and hydroxypropylcellulose, and physicochemical systems such as complexation. Works related to drug delivery and disposition of drugs in humans were carried out at Department of Pharmacy, Kumamoto University Hospital. Topics related to drug delivery in humans include injections containing anticancer drugs for intra-arterial administration, lidocaine gels for dermal anesthesia, glucagon solution for nasal administration. Topics related to disposition of drugs in humans include clinical pharmacokinetic studies in infants and elderly and medical uses of adsorbents.
\end{abstract}

Key words_— biodegradable polymers; gel-forming polymers; hepatic-arterial injection; dermal anesthesia; clinical pharmacokinetics; genetic polymorphism

\section{INTRODUCTION}

The author started his research career as a senior student at Department of Pharmaceutics at Division of Pharmaceutical Sciences, Kyoto University Faculty of Medicine. His research topic was separative determination of isoniazid and its metabolites in the urine. ${ }^{1)} \mathrm{He}$ developed the method using ion exchange resins. After graduating from Master's program in Faculty of Pharmaceutical Sciences, Kyoto University, he was admitted to Graduate School of School of Pharmacy, the University of Wisconsin, he joined the team involving in research on interaction of organic molecules. After Ph.D. degree was granted, he returned to Faculty of Pharmaceutical Sciences, Kyoto University as an assistant and continued his study on molecular interactions. He spent two years in Canada, one year in University of Alberta and

This review article is published on the occasion of retirement from the university in March 2005.

Present address: Guest Professor Room 7320, Student Hall, University of Shizuoka, 52-1 Yada Shizuoka 4228526 Japan.

e-mail: nakano_mshr@yahoo.co.jp another year in Canadian government research laboratories. He was asked to work with Prof. Higuchi in Alza Institute for Pharmaceutical Chemistry where formulation for osmotic pumps was the topic. He got an offer to join Faculty of Pharmaceutical Sciences, Hokkaido University. He was involved in research on modification of drug delivery patterns, either increasing rate of dissolution or prolonging drug release. In Kumamoto University Hospital, he made his effort to improve drug therapy by applying pharmaceutical principles to clinical practice in cooperation with medical doctors. Although he was employed by universities, a government, an industry and a hospital, his areas of activity remained in a broad area of pharmaceutics.

\section{REVIEWS OF RESEARCH WORKS}

Basic Studies on Interactions of Organic Molecules in Solutions The author joined a physical pharmacy research group at University of Wisconsin and studied mechanisms of interaction in solutions under the leadership of Prof. T. Higuchi. The author investigated on methods of calculation of stability constants from data obtained in NMR measurements ${ }^{2)}$ 
and optical activity measurements. ${ }^{3)}$ They studied on solvency and hydrogen bonding interactions in nonaqueous systems. ${ }^{4)}$ Effects of solvent composition on molecular interactions were subjects of a few studies. ${ }^{5,6)}$ Because of importance in clinical practice, more emphasis was placed on mechanisms of interactions in aqueous solutions. ${ }^{7)}$

Because of possible involvement of molecular interactions in biological transport, effect of molecular interactions on permeation rates ${ }^{8,9)}$ was studied.

\section{Studies on Increasing Rate of Dissolution to Obtain}

Better Bioavailability In Chiba University, a new method of preparing amorphous drug by means of grinding a mixture of crystalline drug and microcrystalline cellulose had been established. The author cooperated with Prof. Nakai and his former student, Yamamoto, to find if amorphous forms of drugs are more available after oral administration. Yamamoto and the author ${ }^{10)}$ found that poorly water-soluble griseofulvin showed higher serum concentrations when it was administered in the form of amorphous mixture with micro-crystalline cellulose. Another poorly water-soluble drug, phenytoin ${ }^{11}$ showed higher serum concentrations when a ground mixture with micro-crystalline cellulose was administered than the fine powder of phenytoin alone was administered (Fig. 1).

Sekikawa examined usefulness of polyvinylpyrrolidone in increasing dissolution of drugs such as phenytoin, ${ }^{12)}$ tolbutamide $^{13)}$ and dicumarol ${ }^{14)}$ by

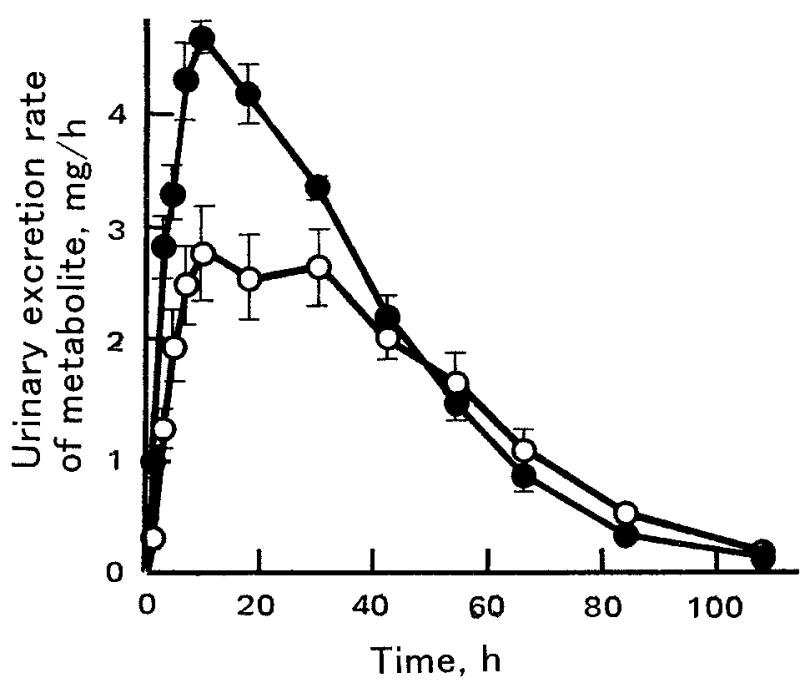

Fig. 1. Urinary Excretion Patterns of Total 5-(p-hydroxyphenyl)-5-Phenylhydantoin after Oral Administration of $250 \mathrm{mg}$ of the Fine Powder $(\mathrm{O})$ and $2500 \mathrm{mg}$ of the Ground Mixture (O) to Five Volunteers ${ }^{11)}$ (Mean \pm S.E.) preparing coprecipitates with the polymer. These drugs dissolved faster from coprecipitates with polyvinylpyrrolidone.

Examination of Biodegradable Polymers for Sustained Drug Release in the Body Since evaluation of biodegradable polymers such as polylactic acid had been made for sustained release of steroid hormones in a few countries, the author started to examine usefulness of polylactic acid for sustained effect of local anesthetics. Wakiyama ${ }^{15)}$ examined preparative methods of microspheres and release patterns of local anesthetic drugs from microspheres. Tetracaine in microspheres showed more prolonged local anesthetic effect ${ }^{16)}$ in comparison with its solution. Since polylactic acids are available in varying molecular weight, influence of physicochemical properties of polylactic acid on the characteristics of microspheres and in vitro release patterns were examined. ${ }^{17)}$ Dibucaine, ${ }^{18)}$ a more potent local anesthetic drug was also examined and showed local anesthetic effect extending for 2 weeks (Fig. 2).

Polycarbonates, synthetic biodegradable materials prepared by Prof. Inoue, Faculty of Engineering, University of Tokyo, were also studied for their usefulness in drug delivery from the point of view of biodegradability and drug permeability by Kawaguchi. Kawaguchi ${ }^{19)}$ found that poly(ethylene carbonate) was degradable in the body while poly (propylene carbonate) was not. In the mixture of poly (ethylene carbonate) and poly (propylene carbonate) ${ }^{20)}$ degradation rate increased with contents of poly(ethylene carbonate) (Fig. 3). Prolonged

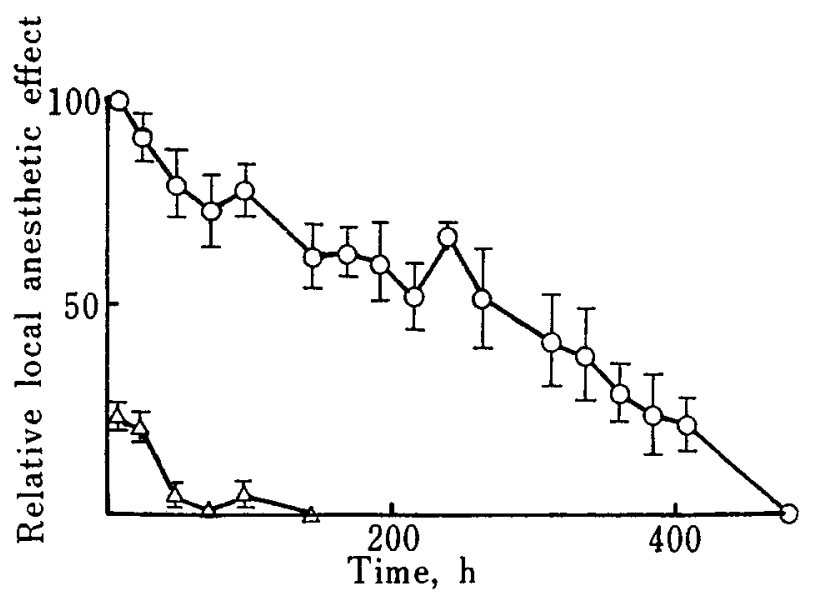

Fig. 2. Relative Local Anesthetic Effects Following Administration of $20 \mathrm{mg}$ of Dibucaine in $56 \mathrm{mg}$ of Microspheres $(\mathrm{O})$ and Drug-free Microspheres $(\triangle)^{18)}($ Mean \pm S.E., $n=6)$ 


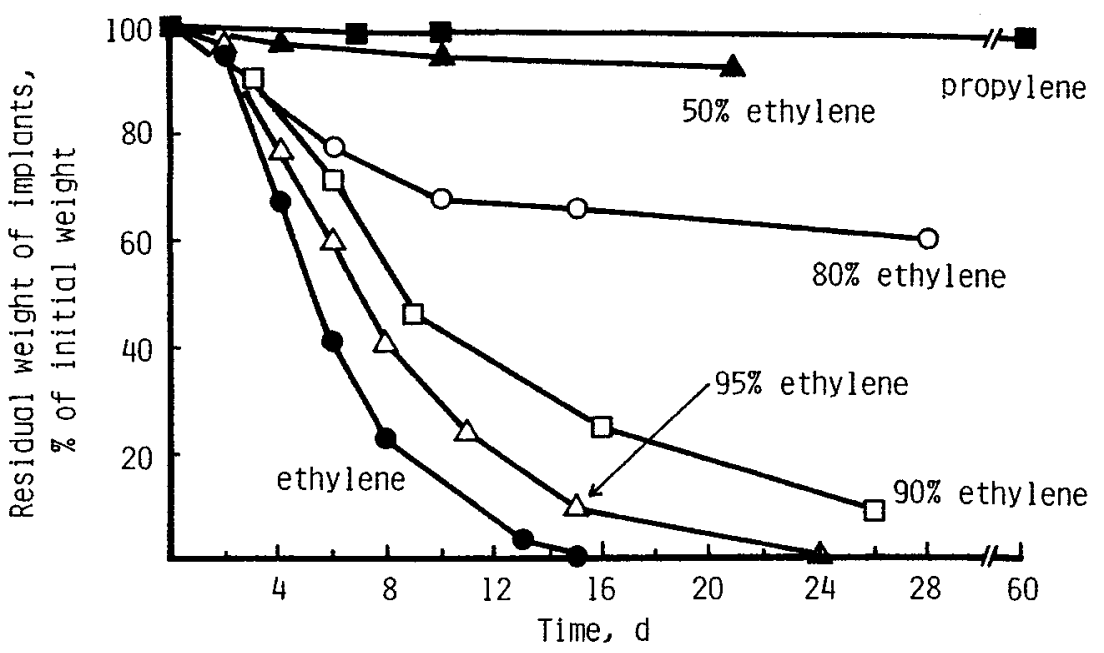

Fig. 3. Biodegradation Profiles of Polycarbonates in the Rat Peritoneal Cavity ${ }^{20)}(n=2)$

plasma levels of tegafur was observed when polycarbonate pellets containing tegafur or FD-1 were implanted into rats. ${ }^{21)}$ The author reviewed on possible use of polycarbonates for drug delivery in a chemical journal. ${ }^{22)}$

Examination of Means for Sustaining Drug Release

1) Gel-forming Materials In order to examine usefulness of naturally available gel-forming materials, we chose konjac gels. Takikawa examined release characteristics of dibucaine ${ }^{23)}$ and theophylline ${ }^{24)}$ from konjac gels. Sustained release of dibucaine in vivo was examined after rectal administration of konjac gels to rats. ${ }^{25)}$

Another naturally available gel-forming material, agar, was examined in the form of beads and sustained release was demonstrated in vitro ${ }^{26)}$ and in vivo. ${ }^{27)}$

A semisynthetic gel-forming polymer, hydroxypropylcellulose was examined ${ }^{28}$ and found that release rate can be modified with mixing ratio of low and high viscosity grade of the polymer, resulting in various patterns of drug levels following oral administration (Fig. 4). This is very useful in controlling drug release since various kinds of polymers are commercially available.

2) Various Physicochemical Systems Juni studied means to prolong release of model drugs through a membrane from various physicochemical systems. The effects of complexation, ${ }^{29)}$ micellar solubilization, ${ }^{30,31)}$ emulsion and cosolvent systems ${ }^{32)}$ on release rate through synthetic membranes were examined.

Injections Containing Anticancer Drugs for Intra- arterial Administration One of responsibility of pharmacists in hospital pharmacy is supply of pharmaceuticals for treatment of patients under various clinical situations. Since developments of new dosage forms and alternative routes of administration are often required in cancer chemotherapy, the author tried to prepare some formulations containing anticancer drugs for intra-arterial administration.

1) Microspheres Containing Aclarubicin for Use as Suspensions Since the author had much experience in preparing microspheres from polylactic acid, Juni tried to prepare microspheres containing aclarubicin, an antibiotic anticancer drug developed in Japan, in polylactic acid matrices. Juni et al. ${ }^{33)}$ found that release rates of aclarubicin from polylactic acid microspheres can be modified by including pharmaceutical additives such as isopropyl myristate in polylactic acid matrices.

Ichihara et al. ${ }^{34)}$ administered the microspheres suspended in a lymphographic agent into hepatic artery of hepatic cancer patients and found that the sizes of tumor were decreased and also $\alpha$-fetoprotein values in sera were decreased. Ichihara et al. ${ }^{35)}$ administered microspheres containing aclarubicin for transcatheter chemoembolization and cisplatin solution for a case of unresectable hepatoblastoma and succeeded in reducing tumor sizes. Beppu et al. ${ }^{36)}$ employed aclarubicin microspheres in combination with cisplatin suspension in an iodized oil for chemoembolization of unresectable hepatocellular carcinoma.

2) Suspensions of Cisplatin in a Lymphographic Agent Fukushima et al. ${ }^{37)}$ examined anticancer activity of cisplatin suspended in a lymphographic 


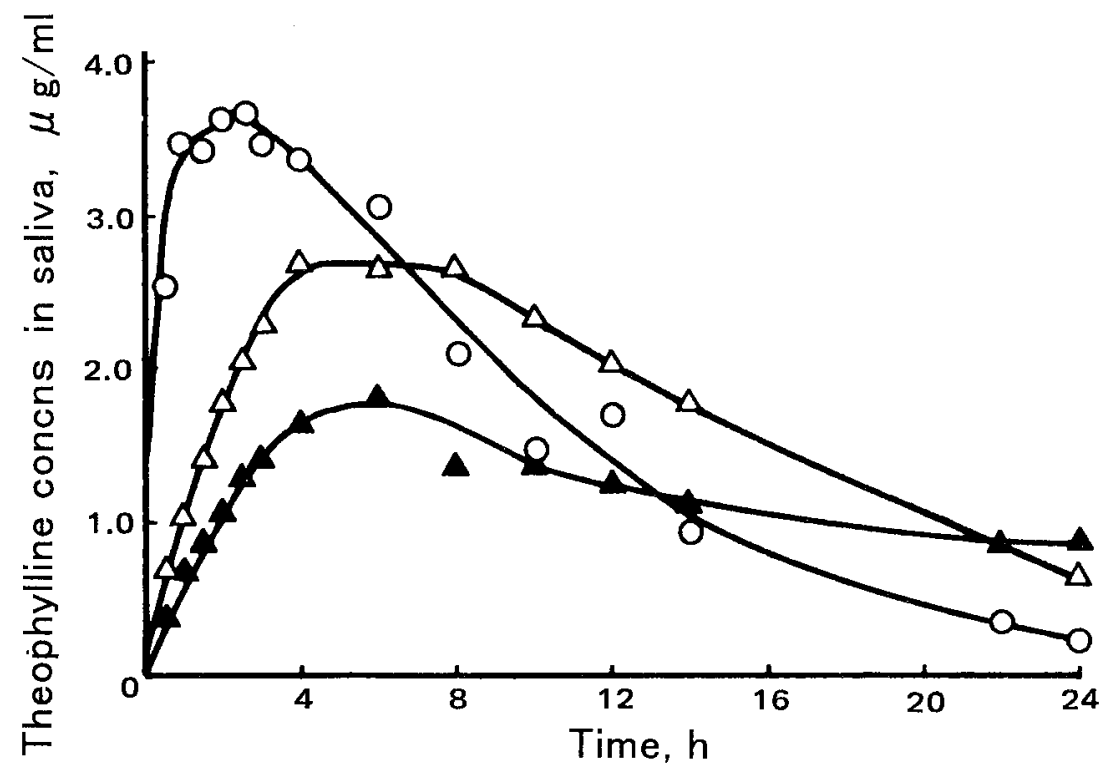

Fig. 4. Salivary Level Profiles of Theophylline Following Administration of $250 \mathrm{mg}$ of Theophylline Powders ( $(\mathrm{)})$ and $250 \mathrm{mg}$ of Theophylline-250 mg of Hydroxypropylcellulose (1:1 Mixture of Low- and Medium-grade Polymers $(\triangle)$ or Medium-viscosity Grade Polymer Alone $(\boldsymbol{\Delta})$ ) Tablets to Five Volunteers ${ }^{28)}$ (Average values)

agent by administering it into hepatic artery in rabbits bearing experimental tumor VX-2 and found much accumulation of cisplatin in tumor compared to that in nontumor areas. When Shibata et al. ${ }^{38-41)}$ administered cisplatin suspended in an oily lymphographic agent to patients suffering from hepatic cancer, they observed much reduction in $\alpha$-fetoprotein values in sera.

3) Solutions of a Lipophilic Floxuridine Derivative in a Lymphographic Agent Fukushima et al. ${ }^{42)}$ found selective anticancer effect of $3^{\prime}, 5^{\prime}$-dioctanoyl-5-floxuridine, a lipophilic prodrug of floxuridine (5-fluoro-2-deoxyurdine), dissolved in an oily lymphographic agent on hepatic cancer of rabbits bearing VX-2 tumor. Kawaguchi et al. ${ }^{43)}$ found selective accumulation of the same prodrug and sustained release of its active metabolites in VX-2 rabbit hepatoma following intra-arterial administration of the prodrug solution in a lymphographic agent, Lipiodol.

Yamashita et al. ${ }^{44)}$ intra-arterially infused the prodrug dissolved in a lymphographic agent to patients suffering from malignant liver tumors and found reduction in serum tumor markers such as $\alpha$ fetoprotein (Fig. 5) and carcinoembryonic antigen. They obtained 3 cases of complete remission and 11 cases of partial remission among 29 patients suffering from hepatocellular carcinoma.

Lidocaine Gels for Dermal Anesthesia Although a preparation for dermal anesthesia contain- ing an eutectic mixture of lidocaine and prilocaine had been marked abroad, and preparations for mucous anesthesia are available in Japan, no such preparation for dermal anesthesia was marketed in Japan. Because of adverse reaction by prilocaine, use of lidocaine-prilocaine mixture (EMLA) is not justified any more. The author therefore tried to design a dermal preparation employing lidocaine in hydrophilic gel.

Mishima et al. ${ }^{45)}$ reported their data on dermal anesthesia in human volunteers in 1989 at 5 th symposium on transdermal preparations. Thereafter clinicians examined usefulness of $10 \%$ lidocaine in aqueous gel and they reported on prevention of pain from dermal puncture (Nakamura et al., ${ }^{46,47)}$ Hashiguchi et $\mathrm{al}^{48)}$ ), from venous cannulation (Kano et al., ${ }^{49,50)}$ Kitamoto et al. ${ }^{51)}$ ), for reduction of pain prior to cryotherapy of dermal melanocytosis (Nakamura et al. ${ }^{52)}$, for management of pain associated with herpes zoster (Shimoda et al. ${ }^{53)}$ ), for pain-free self-injection of human growth hormone (Iwatani et al. ${ }^{54)}$ ). Kitamoto et al. ${ }^{51}$ ) showed that reduction in pain by dermal anesthesia during dermal puncture was apparent in $30 \mathrm{~min}$.

Nakano and $\mathrm{Kano}^{55)}$ reviewed areas where application of dermal anesthesia can be useful. Kano et al. ${ }^{56,57)}$ examined on shortening of onset of dermal patch anesthesia by pretreatment of skin and on penetration depth of lidocaine from the transdermally 


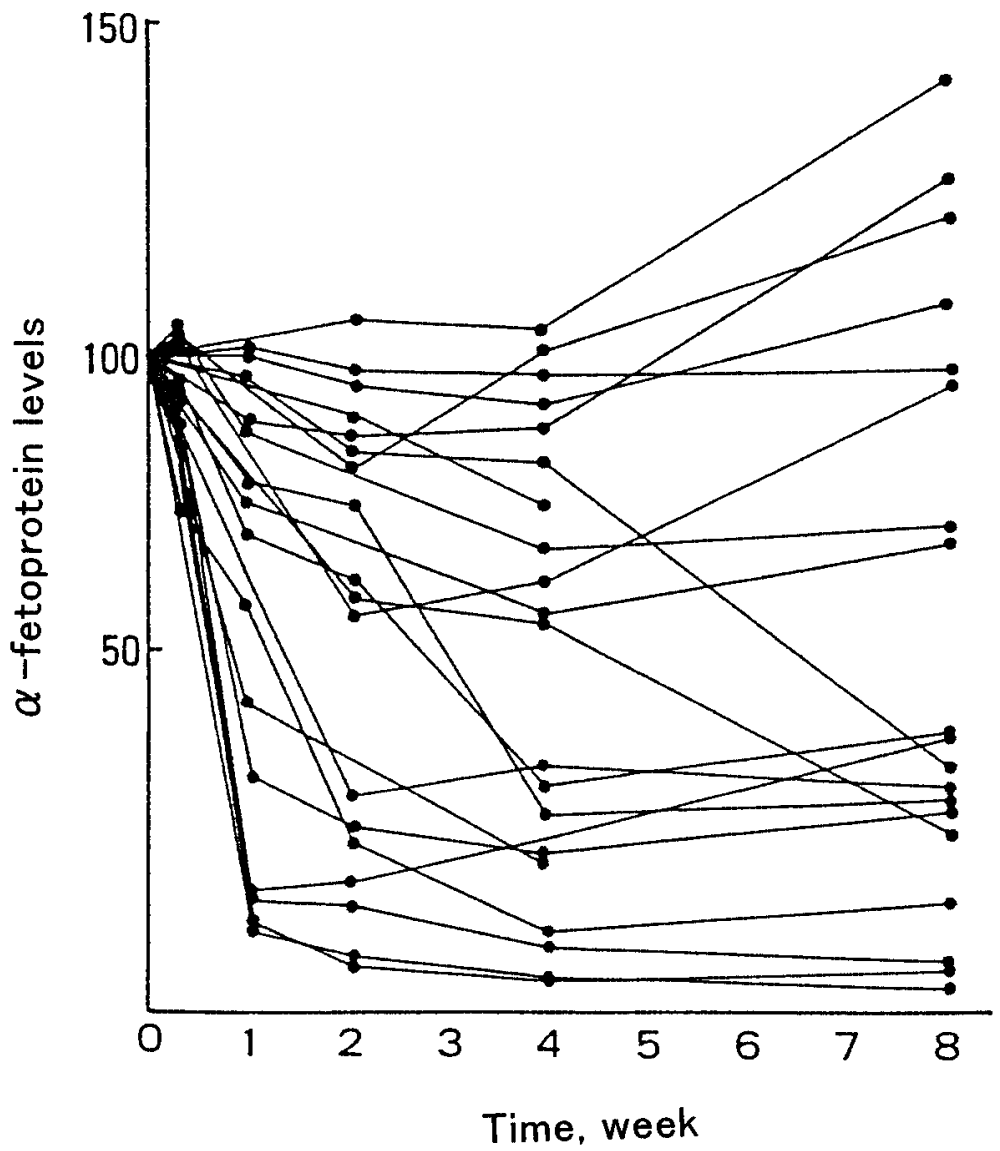

Fig. 5. $\alpha$-fetoprotein Levels in Patients with Hepatocellular Carcinomas before and after Treatment with $3^{\prime}, 5^{\prime}$-Dioctanoyl-5-Fluoro2 -Deoxyuridine in Lipiodol ${ }^{44)}$

applied lidocaine gel. Sakamoto et al. ${ }^{58)}$ found lidocaine gel be as effective as or even better than the EMLA cream marketed in Europe and U.S.A.

Glucagon Solution for Nasal Administration in a Pancreatectomized Patient Since polypeptides are digested in gastrointestinal tract and intestinal mucosa when they are administered orally, they are injected clinically. When pancreas are removed to treat pancreatic tumor, both insulin and glucagon are administered parenterally. Surgeons wanted to give glucagon through non-parenteral routes.

Mishima et al. ${ }^{59)}$ examined enhancing effect of absorption enhancers in rats and found that both glycocholate and caprate were effective in enhancing absorption of glucagon in rats. Hirota et al. ${ }^{60}$ ) administered glucagon solution containing caprate into nasal cavity of a patient who underwent total pancreatectomy and detected sufficient levels of immunoreactive glucagon in plasma.

Clinical Pharmacokinetic Studies The author believes that pharmacokinetic information is a basis of designing dosage regimens and studies on disposi- tion of drugs in patients differing in physiological and pathological states are important topics for pharmacists and doctors.

1) Pharmacokinetics of Cephem Antibiotics in Newborns Since only few pharmacokinetic studies in infants had been carried out, the author felt that he should add more information to their knowledge on disposition of drugs in infants. Nakamura et al. ${ }^{61)}$ studied pharmacokinetis of cefmenoxime (Fig. 6) after establishment of a very sensitive assay procedure of the drug in small volume of sera obtainable from infants. She found that clearance ratio of cefmenoxime increased with increase in postconceptional age and reached the plateau value, an adult value, at 10 month after birth. Nakamura et al. ${ }^{62)}$ obtained similar results with another cephem antibiotic, ceftizoxime in newborns.

2) Pharmacokinetics of Famotidine and Roxatidine in the Elderly and Kidney Failure Patients Famotidine is eliminated mainly by excretion but it tends to cause neurological adverse reactions in the elderly patients even if they are not diagnosed to be 


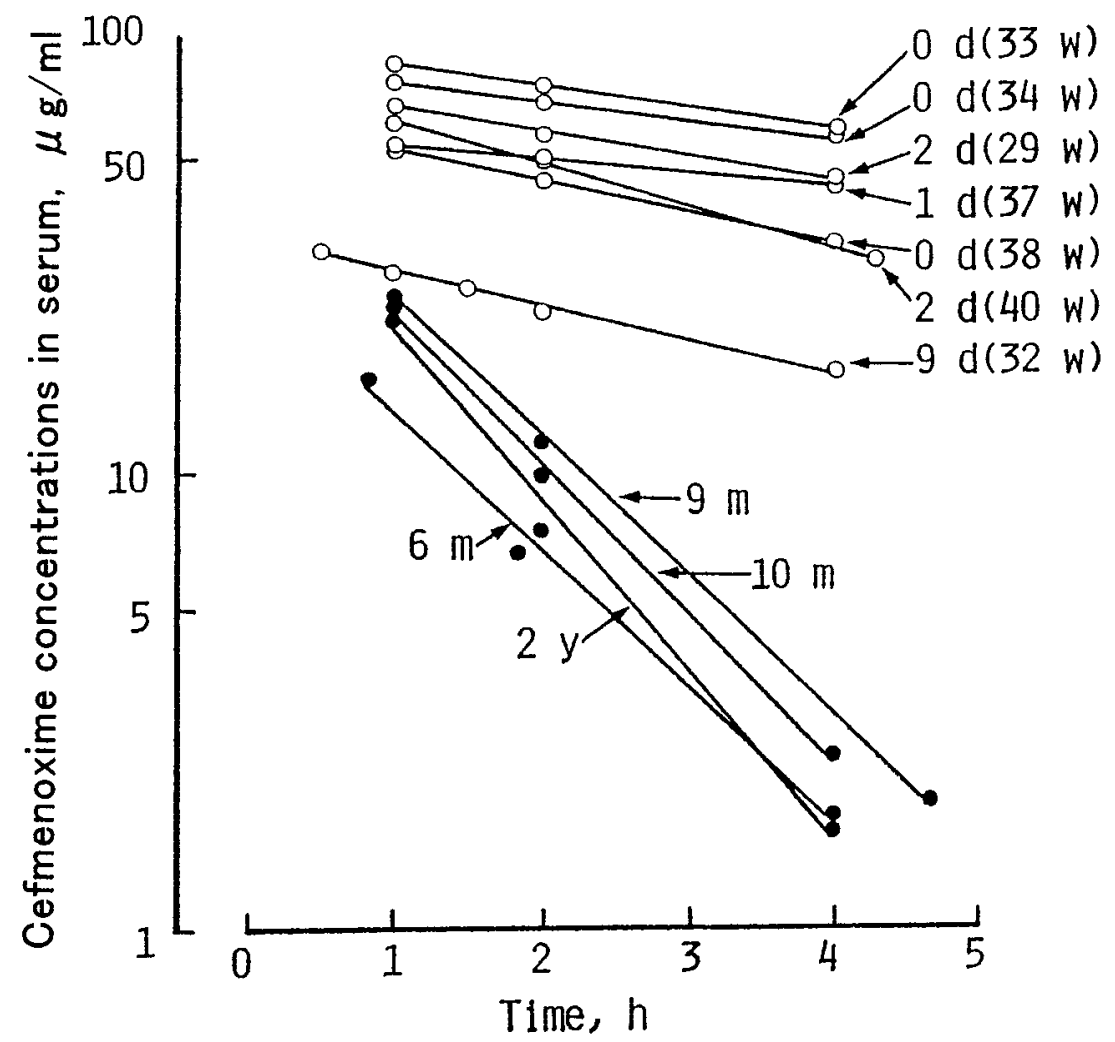

Fig. 6. Serum Concentration-time Profiles of Cefmenoxime after I.V. Administration ${ }^{61)}$

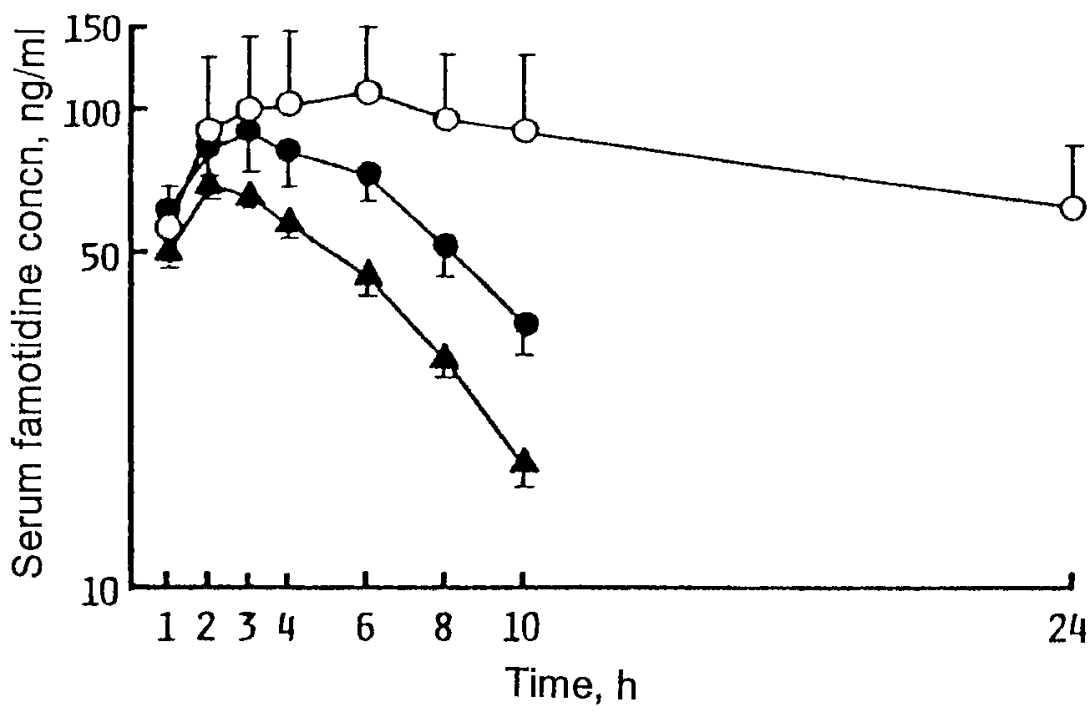

Fig. 7. Mean Concentrations of Famotidine after Oral Administration of One Tablet Containing 20 mg of Famotidine to Five Elderly Patients with Renal Insufficiency $(\bigcirc)$, to Ten Elderly Patients with Normal Renal Function $(\mathbf{O})$ and to Six Healthy Young Volunteers $(\boldsymbol{\Delta})^{63)}$

suffering from renal failure. Therefore the author studied pharmacokinetis of famotidine in the elderly patients.

Inotsume et al. ${ }^{63)}$ found that clearance of the drug in elderly patients was smaller than that in young adults after oral administration (Fig. 7). This is explained by observation that renal function is decreased in the elderly even if they do not suffer from renal failure. Inotsume et al. ${ }^{64)}$ also studied pharmacokinetics of famotidine following intravenous ad- 
ministration to elderly patients as well as to healthy young volunteers.

Inotsume et al. ${ }^{65)}$ studied on possible removal of famotidine by hemodialysis in elderly anuric patients. They found that about $42 \%$ of famotidine was removed by dialysis when dialysis was carried out for the first $5 \mathrm{~h}$ after drug administration.

Katsuki et al. ${ }^{66)}$ studied pharmacokinetics of roxatidine, another histamine $\mathrm{H}_{2}$ antagonist, in patients suffering from renal failure and in healthy volunteers. Serum concentrations remained high even after $24 \mathrm{~h}$ in renal failure patients.

3) Stereospecific Disposition of Enantiomers Since enantiomers may differ from each other in pharmacological activity, studies of possible difference in disposition among enantiomers are important.

Minami et al. ${ }^{67)}$ carried out stereoselective analysis of disposition of tosufloxacin enantiomers in humans and found a small difference among them, maximum concentration of $(-)$-form and clearance of $(+)$ form being greater than the other.

Inotsume et al. ${ }^{68)}$ investigated pharmacokinetics of nicardipine enantiomers in healthy young volunteers and found more than twice as high maximum concentrations and more than twice as much areas under concentration curves of (+)-nicardipine as (-)nicardipine. Iwaoka et al. ${ }^{69)}$ found correlation of concentrations of $(+)$-nicardipine with antihypertensive effects after oral administration of racemic nicardi- pine.

Katsuki et al. ${ }^{70)}$ developed a method of separate determination of $\mathrm{R}(+)$ - and $\mathrm{S}(-)$-lansoprazole and used the method of separation to find possible difference in pharmacokinetic behaviors among the enantiomers. They found that $\mathrm{R}(+)$-lansoprazole showed about 3 times as high maximum concentrations as $\mathrm{S}$ (-)-form (Fig. 8). Because of possible difference in pharmacological activity among the enantiomers of lansoprazole, this finding can be important.

\section{4) Genetic Polymorphism of Lansoprazole}

In omeprazole which had been developed in Europe, genetic polymorphism has been reported. For lansoprazole which had been developed in Japan, the author examined if similar phenomenon is observable. Katsuki et al. ${ }^{71)}$ found from data obtained (Fig. 9), two phenotypes, Group 1 and Group 2 among subjects when they calculated lansoprazole/5-hydroxylansoprazole and lansoprazole/lansoprazole sulfone ratios. When they carried out genetic analysis for cytochrome P-450 2C19, they found $\mathrm{wt} / \mathrm{m} 2$ and $\mathrm{wt} /$ $\mathrm{m} 1$ in Group 1 and $\mathrm{m} 1 / \mathrm{m} 1$ and $\mathrm{m} 1 / \mathrm{m} 2$ in Group 2 . Thus extensive metabolism to 5-hydroxylansoprzole in Group 1 and poor metabolism to the same metabolite in Group 2 can be explained from results in genetic analysis

Medical Use of Adsorbents Arimori et al. ${ }^{72)}$ showed accelerated clearance of intravenously administered theophylline and phenobarbital by oral

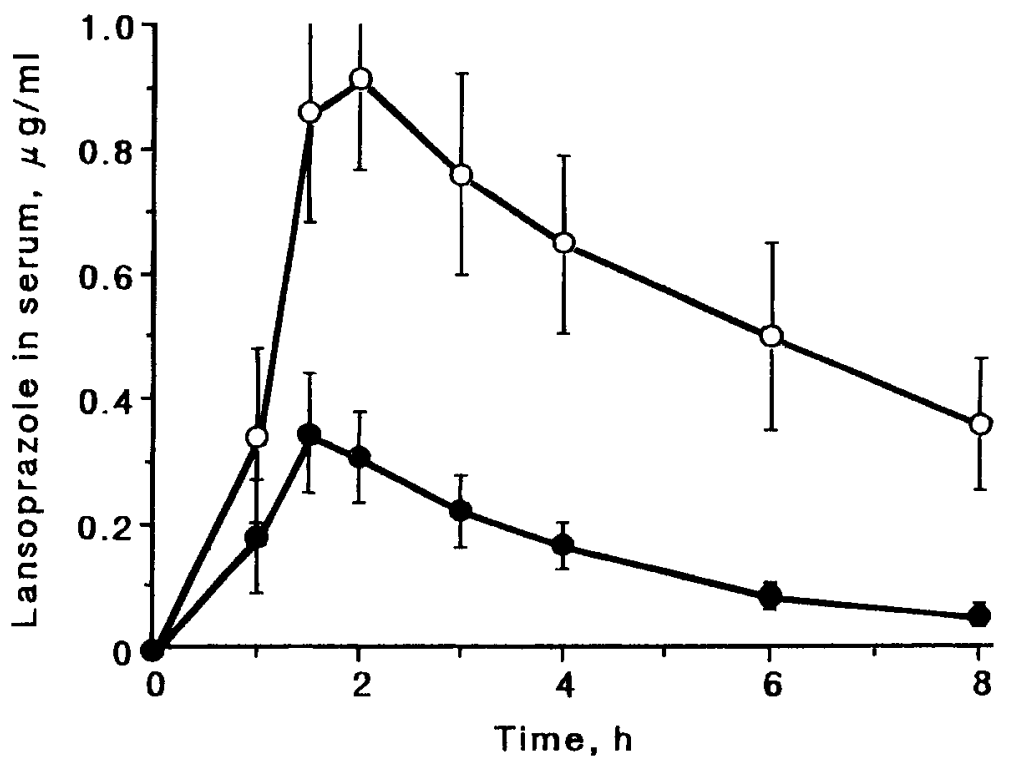

Fig. 8. Mean Concentrations of $\mathrm{R}(+)$-lansoprazole $(\mathrm{O})$ and $\mathrm{S}(-)$-lansoprazole $(\mathrm{O})$ in Serum after Oral Administration of a Commercial Lansoprazole Capsule Containing $30 \mathrm{mg}$ of Racemic Lansoprazole to Six Healthy Volunteers ${ }^{70)}$ 
a)

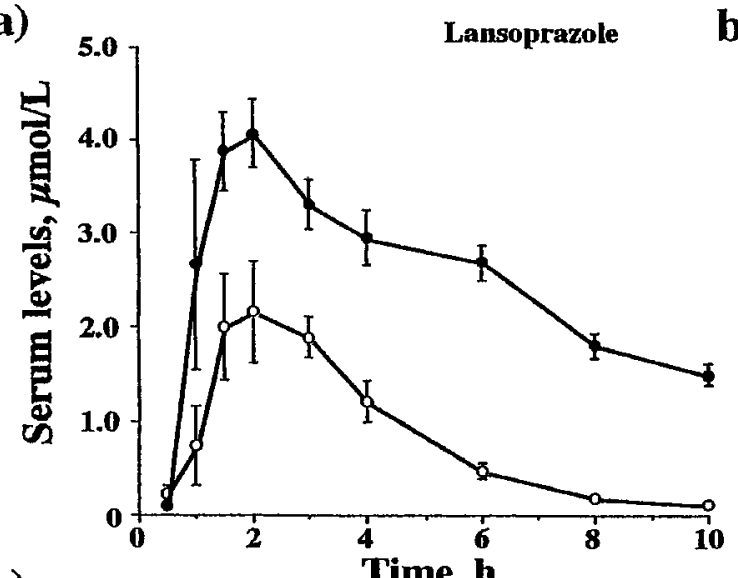

c)

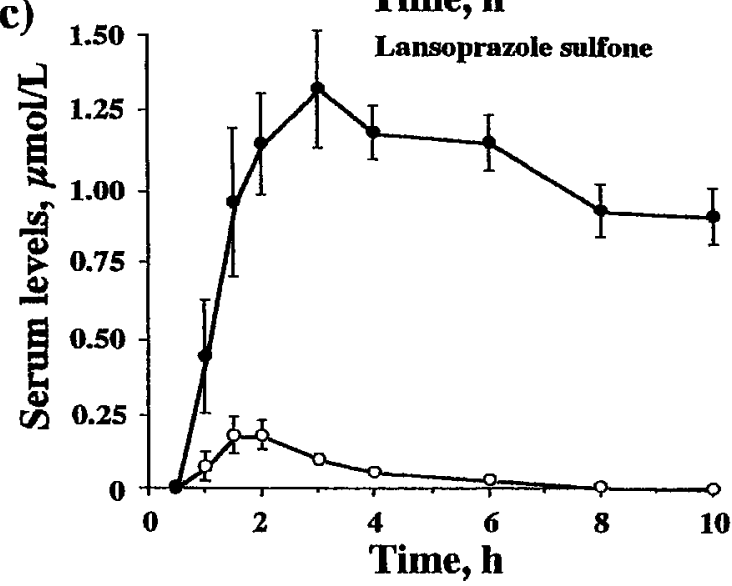

b)

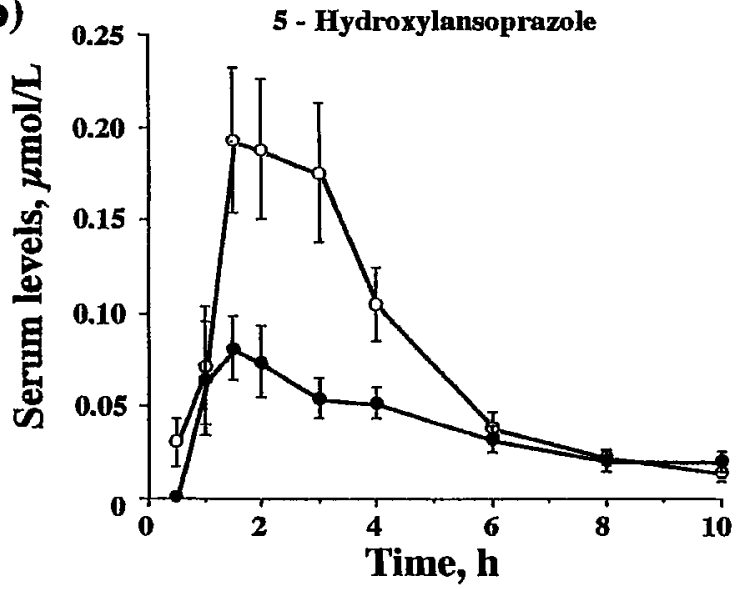

Fig. 9. Mean Concentrations of Lansoprazole (a), 5-hydroxylansoprazole (b) and Lansoprazole Sulfone (c) after Oral Administration of a Capsule Containing $30 \mathrm{mg}$ of Lansoprazole to Five Subjects in Group 1 (O) and Three Subjects in Group 2

doses of activated charcoal in rats. They showed that drugs exsorbed through intestinal mucosa or excreted in a bile juice into the upper part of the intestine, can be adsorbed to an adsorbent orally administered. In this way drugs in the blood can be pulled out into the gastrointestinal tract. This approach has been named gastrointestinal dialysis. Arimori et al. ${ }^{73)}$ examined possible removal of disopyramide already absorbed into the blood back into the intestinal tract by administration of activated charcoal. They showed that a half-life of disopyramide was shortened and clearance was increased by oral dose of activated charcoal $5 \mathrm{~h}$ after oral administration of disopyramide.

Inotsume et al. ${ }^{74)}$ succeeded in accelerating elimination of phenobarbital by oral administration of activated charcoal suspensions in an overdosed patient.

Honda et al. ${ }^{75-78)}$ demonstrated partial prevention of gastrointestinal absorption of theophylline, phenytoin, nalidixic acid, quinidine and phenobarbital by oral administration of activated carbon beads as an oral adsorbent. Beads encapsulating a cation ex- change resin ${ }^{79)}$ also decreased absorption of quinidine.

Efforts to Improve Clinical Trials in Japan The author felt that systems to support clinical research in Japan have to be improved.

Therefore the author made survey on education related to clinical research, ${ }^{80}$ functions of institutional review boards, ${ }^{81-83)}$ and role of research subject advocates $^{84}$ in the United States.

The author visited clinical research centers and attended IRBs in a few American universities to get information on current states of the systems. During the stay in the United States, opening of a website to exhibit results of clinical trials ${ }^{85)}$ was found.

A lecture on clinical research coordinators started in 2002 as a part of advanced pharmacotherapy lectures. Clinical trials/clinical drug development course opened as evening lectures opened to public in 2004.

\section{CONCLUSION}

The author feels that understanding of basic princi- 
ples in physical chemistry is important to invent new pharmaceutical preparations such as fast dissolving preparations and sustained-release preparations. Cooperation with medical doctors is important for some new formulations to be examined in clinical settings and dispositions of drugs to be examined in patients because behaviors of pharmaceutical preparations and dispositions of drugs in humans can be different from those in experimental animals.

Acknowledgements Works included in this review have become possible by the help of students, fellow pharmacists and cooperation with medical doctors. I would like to express my sincere appreciation to the individuals whose names are referred in the references listed below for cooperation in carrying works cited in this review.

\section{REFERENCES}

1) Kakemi K., Arita T., Sezaki H., Nakano M., Kiriyama T., J. Pharm. Soc. Jap., 82, 195-200 (1962).

2) Nakano M., Nakano N. I., Higuchi T., J. Phys. Chem., 71, 3954-3959 (1967).

3) Nakano M., Higuchi T., J. Pharm. Sci., 57, 1865-1868 (1968).

4) Higuchi T., Richard J. H., Davis S. S., Kamada A., Hou J. P., Nakano M., Nakano N. I., Pitman I. H., J. Pharm. Sci., 58, 661-671 (1969).

5) Kakemi K., Sezaki H., Suzuki E., Nakano M., Chem. Pharm. Bull., 17, 242-247 (1969).

6) Kristiansen H., Nakano M., Nakano N.I., Higuchi T., J. Pharm. Sci., 59, 1103-1106 (1970).

7) Nakano M., Higuchi T., J. Pharm. Sci., 57, 183-184 (1968).

8) Nakano M., Patel N.K., J. Pharm. Sci., 59, 77 -81 (1970).

9) Nakano M., J. Pharm. Sci., 60, 571-575 (1971).

10) Yamamoto K., Nakano M., Arita T., Nakai Y., J. Pharmacokin. Biopharmaceut., 2, 487493 (1974).

11) Yamamoto K., Nakano M., Arita T., Takayama Y., Nakai Y., J. Pharm. Sci., 65, 14841488 (1976).

12) Sekikawa H., Naganuma T., Fujiwara J., Nakano M., Arita T., Chem. Pharm. Bull.,
26, 3033-3039 (1978).

13) Sekikawa H., Naganuma T., Fujiwara, J., Nakano M., Arita T., Chem. Pharm. Bull., 27, 31-37 (1979).

14) Sekikawa H., Fukuda N., Takada M., Ohtani K., Arita T., Nakano M., Chem. Pharm. Bull., 31, 1350-1356 (1983).

15) Wakiyama N., Juni K., Nakano M., Chem. Pharm. Bull., 29, 3363-3368 (1981).

16) Wakiyama N., Nakano M., J. PharmacobioDyn., 5, 13-17 (1982).

17) Wakiyama N., Juni K., Nakano M., Chem. Pharm. Bull., 30, 2621-2628 (1982).

18) Wakiyama N., Juni K., Nakano M., Chem. Pharm. Bull., 30, 3719-3727 (1982)

19) Kawaguchi T., Nakano M., Juni K., Inoue S., Yoshida Y., Chem. Pharm. Bull., 30, 15171520 (1982).

20) Kawaguchi T., Nakano M., Juni K., Inoue S., Yoshida Y., Chem. Pharm. Bull., 31, 14001403 (1983).

21) Kawaguchi T., Nakano M., Juni K., Inoue S., Yoshida Y., Chem. Pharm. Bull., 31, 41574160 (1983).

22) Nakano M., Organic Synthetic Chemistry (YuukiGouseiKagaku), 42, 665-671 (1984).

23) Nakano M., Takikawa K., Arita T., J. Biomed. Mater. Res., 13, 811-819 (1979).

24) Nakano M., Takikawa K., Juni K., Arita T., Chem. Pharm. Bull., 27, 2834-2837 (1979).

25) Nakano M., Takikawa K., Arita T., Chem. Pharm. Bull., 27, 2501-2503 (1979).

26) Nakano M., Nakamura Y., Takikawa K., Kouketsu M., Arita T., J. Pharm. Pharmacol., 31, 869-872 (1979).

27) Nakano M., Kouketsu M., Nakamura Y., Juni K., Chem. Pharm. Bull., 28, 2905-2908 (1980).

28) Nakano M., Ohmori N., Ogata A., Sugimoto K., Tobino Y., Iwaoku R., Juni K., J. Pharm. Sci., 72, 378-380 (1983).

29) Nakano M., Juni K., Arita T., J. Pharm. Sci., 65, 709-712 (1976).

30) Juni K., Nakano M., Arita T., Chem. Pharm. Bull., 25, 2807-2811 (1977).

31) Juni K., Tomitsuka T., Nakano M., Arita T., Chem. Pharm. Bull., 26, 837-841 (1978).

32) Juni K., Nomoto K., Nakano M., Arita T., J. Memb. Sci., 5, 295-304 (1979). 
33) Juni K., Ogata J., Matsui N., Kubota M., Nakano M., Chem. Pharm. Bull., 33, 17341738 (1983).

34) Ichihara T., Akagi, M., Mori M., Beppu T., Nakano M., Kojima T., "Cancer Chemotherapy with Arterial Injection, 2nd ed.,' eds. by Taguchi T., Nakamura H, Cancer and Chemotherapy Publisher, Tokyo, 1988, pp. 334-341.

35) Ichihara T., Akagi M., Mori M., Sera Y., Ikei S., Sakamoro K., Ikeda S., Yamamoto T., Nakano M., Juni K., Jpn. J. Pediat. Surg., 19, 955-961 (1987).

36) Beppu T., Ohara C., Yamaguchi Y., Ichihara T., Yamanaka T., Katafuchi S., Ikei S., Mori K., Fukushima S., Nakano M., Ogawa M., Cancer, 68, 2555-2560 (1991).

37) Fukushima S., Kishimoto S., Hayashi Y., Kaneko M., Nakano M., Shibata J., Fujiyama S., Sato T., J. Jpn. Soc. Cancer Ther., 23, 2743-2749 (1988).

38) Shibata J., Nakazono K., Fujiyama S., Sato T., Fukushima S., Hayashi Y., Kishimoto S., Nakano M., Drug Delivery System, 3, 431-435 (1988).

39) Shibata J., Kimura S., Chikazawa H., Miyase S., Sakai M., Morishita T., Fujiyama S., Sato T., Fukushima S., Kishimoto S., Nakano M., J. Jpn. Soc. Cancer Ther., 3, 2750-2759 (1988).

40) Shibata J., Fujiyama S., Sato T., Kishimoto S., Fukushima S., Nakano M., Cancer, 64, 1586-1594 (1989).

41) Shibata J., Chikazawa H., Goshi K., Fujiyama S., Sato T., Fukushima S., Kishimoto S., Nakano M., Drug Delivery System, 5, 33-37 (1990).

42) Fukushima S., Kawaguchi T., Nishida M., Juni K., Yamashita Y., Takahashi M., Nakano M., Cancer Res., 47, 1930-1934 (1987).

43) Kawaguchi T., Fukushima S., Hayashi Y., Kaneko M., Nakano M., Cancer Res., 48, 4179-4183 (1988).

44) Yamashita Y., Takahashi M., Bussaka H., Fukushima S., Kawaguchi T., Nakano M., Cancer, 64, 2437-2444 (1989).

45) Mishima M., Shimoyama H., Nakano M., Kano T., Hashiguchi A., Nakamura M., Morioka T., Proceeding of papers presented at 5th Symposium on Percutaneous Absorption Preparations, held on Oct., 1989, Ther. Res., 11, 647 (1990).

46) Nakamura M., Kano T., Hashiguchi A., Shimoda O., Kato K., Shimizu Y., Morioka T., Mishima M., Yasutake S., Nakano M., Jpn. J. Anesth., 39, 568-571 (1990).

47) Nakamura M., Kano T., Sakamoto M., Shimoda O., Morioka T., Mishima M., Nakano M., Kumamoto Med. J., 44, 111-122 (1993).

48) Hashiguchi A., Kano T., Nakamura M., Shibata Y., Sasaoka Y., Matsuyama K., Morioka T., Mishima M., Yasutake S., Nakano M., Jpn. J. Anesth., 39, 473-477 (1990) .

49) Kano T., Hashiguchi A., Nakamura M., Morioka T., Mishima M., Nakano M., Anesth. Analg., 74, 535-538 (1992).

50) Kano T., Nakamura M., Hashiguchi A., Morioka T., Mishima M., Nakano M., Anaesthesia, 47, 708-710 (1992).

51) Kitamoto Y., Kano T., Mishima M., Matsushita K., Yasumoto N., Nakano M., Morioka T., Sato T., Am. J. Kidney Dis., 20, 489491 (1992).

52) Nakamura T., Ono T., Yoshimura K., Nakamura M., Hashiguchi A., Shimoda O., Ezaki K., Mishima M., Yasutake S., West. Jpn. J. Dermatol., 52, 743-746 (1990).

53) Shimoda O., Kano T., Takaki M., Tashima T., Tashiro M., Ikuta Y., Morioka T., Nakano M., Mishima M., Jpn. J. Anesth., 42, 1171 -1176 (1993).

54) Iwatani N., Kodama M., Miike T., Kano T., Nakano M., Mishima M., Tsuzuki O., Clin. Pediatr. Endocrinol., 3, 113-116 (1994).

55) Nakano M., Kano T., Dermal Anesthesia, Jpn. J. Clin. Anesth., 17, 617-622 (1993).

56) Kano T., Nakamura M., Hashiguchi A., Sadanaga M., Morioka T., Mishima M., Nakano M., Anesth. Analg., 75, 555-557 (1992).

57) Kano T., Nakamura M., Hashiguchi A., Masuda K., Morioka T., Mishima M., Nakano M., J. Anesth., 7, 21-26 (1993).

58) Sakamoto M., Kano T., Sadanaga S., Shimoda O., Morioka T., Mishima M., Nakano M., Anaesthesia, 48, 390-392 (1993).

59) Mishima M., Wakita Y., Nakano M., Hirota 
M., Ikei S., Akagi M., J. Clin. Exper. Med., 140, 223-224 (1987).

60) Hirota M., Ikei S., Mishima M., Mori K., Sakamoto K., Yamane T., Idegami K., Katafuji S., Kiyohara H., Nakashima Y., Nakano M., Akagi M., Jpn. J. Surg., 19, 586592 (1989).

61) Nakamura C., Higashi A., Ikeda T., Iribe K., Inotsume N., Nakano M., Matsuda I., Jpn. J. Clin. Pharmacol. Ther., 20, 421-426 (1989).

62) Nakamura C., Inotsume N., Nakano M., Higashi A., Matsuda I., Ikeda T., Iribe K., Jpn. J. Develop. Pharmacol. Ther., 2, 72 (1989).

63) Inotsume N., Nishimura M., Fujiyama S., Sagara K., Sato T., Imai Y., Matsui H., Nakano M., Eur. J. Clin. Pharmacol., 36, 517-520 (1989).

64) Inotsume N., Oniki M., Takeshita S., Fujiyama S., Sato T., Matsushita K., Nakano M., Jpn. J. Clin. Pharmacol. Ther., 25, 563-567 (1994).

65) Inotsume N., Nishimura M., Nakano M., Fujiyama S., .Sagara K., Sato T., Matsushita K., Imai Y., Matsui H., Eur. J. Pharmacol., 38, 313-314 (1990).

66) Katsuki H., Inotsume H., Nakano M., Matsushita K., Takeshita S., Fujiyama S., Jpn. J. Clin. Pharmacol. Ther., 25, 577-582 (1994).

67) Minami R., Inotsume N., Nakamura C., Nakano M., Eur. J. Clin. Pharmacol., 54, 489 -491 (1993).

68) Inotsume N., Iwaoka T., Honda M., Nakano M., Okamoto Y., Naomi S., Tomita K., Teramura T., Higuchi S., Eur. J. Clin. Pharmacol., 52, 289-292 (1997).

69) Iwaoka T., Inotsume N., Inoue J., Naomi S., Okamoto Y., Higuchi S., Nakano M., Umeda T., Eur. J. Clin. Pharmacol., 48, 345-349 (1995).

70) Katsuki H., Yagi H., Arimori K., Nakamura
C., Nakano M., Katafuji S., Fujioka Y., Fujiyama S., Pharm. Res., 13, 611-615 (1996).

71) Katsuki H., Nakamura C., Arimori K., Fujiyama S., Nakano M., Eur. J. Clin, Pharmacol., 52, 391-396 (1997).

72) Arimori K., Nakano M., J. PharmacobioDyn., 9, 437-441 (1986).

73) Arimori K., Kawano H., Nakano M., Int. J. Clin. Pharmacol. Ther. Toxicol., 27, 280-284 (1989).

74) Inotsume N., Kimoto A., Katsuya H., Nakano M., Higashi A., Jpn. J. Clin. Pharmacol. Ther., 19, 779-781 (1988).

75) Honda Y., Iwaoku R., Nakano M., Nakano N. I., J. Clin. Exper. Med., 127, 1131-1132 (1983).

76) Honda Y., Nakano N.I., Iwaoku R., Nakano M., J. Clin. Exper. Med., 15, 305-306 (1984).

77) Honda Y., Nakano M., Nakano N. I., J. Pharmacobio-Dyn., 13, 597-601 (1990).

78) Honda Y., Nakano M., Nakano N.I., Chem. Pharm. Bull., 34, 4385-4388 (1986).

79) Honda Y., Iwaoku R., Nakano N.I., Nakano M., Jpn. J. Clin. Pharmacol. Ther., 15, 437443 (1984).

80) Nakano M., Nakano M., Jpn. J. Clin. Pharmacol. Ther., 33, 201S-202S (2002).

81) Nakano M., Nakano M., Jpn. J. Clin. Pharmacol. Ther., 34, 31S-32S (2003).

82) Nakano M., Nakano M., Jpn. J. Clin. Pharmacol. Ther., 34, 179S-180S (2003).

83) Nakano M., Tanaka T., Nakano M., Jpn. J. Clin. Pharmacol. Ther., 35, 136S-137S (2004).

84) Matsumoto K., Ohashi K., Sakurai K., Hiramatsu H., Yamamoto M., Inoue K., Nakano M., Jpn. J. Clin. Pharmacol. Ther., 35, S191 (2004).

85) Nakano M., Jpn. J. Clin. Pharmacol. Ther., 35, 311-312 (2004). 